\title{
EFFECT OF STARTING PROGESTERONE SUPPORT ON THE DAY BEFORE VERSUS THE DAY OF EMBRYO TRANSFER ON THE OUTCOME OF ICSI CYCLES
}

Ashraf Hany Abd El Rahman, M.D., Hadeer Aly Abbassy. M.D.

Obstetrics \& Gynecology Departement \& Clinical and Chemical pathology departerment

faculty of medicine, Alexandria University, EGYPT

\section{ABSTRACT}

Objective:: To compare the effect of two different times of onset of lutcal phase support on ongoing pregnancy ritte in infertile patients undergoing treatment with GnRH down-legulated IVF and embryo transfer (IVF/ET).

Design: prospective randomized trial.

Setting : Assisted reproductive technology program at the shatby university hospital for women, and Madina infertility Privale center in Alexandria.

Patients : one hundred and forty patients undergoing IVF-ICSI program.

Intervention: All patients planned to undergo their first IVF treatment cycle were randomly allocated to receive parentral progesterone as luteal support at two different time points, that is, the day belore embryo transfer (ET) and at the day of ET. The primary endpoint of this study was ongoing pregnancy rate.

Main outcome Measures: Clinical pregnancy rates.

Results : A total of 140 women were randomized; 70 were allocated to the day before embryo transfer group, and 70 to the group of the day of ET. An ongoing pregnancy rate was $22.7 \%$ in the day before embryo transfer group versus $23.6 \%$ at the day ET group, respectively.

Conclusion : We could not identify, within the chosen time points and within the sample size, a specific implantation window period in which an optimal endometrial receptivity yiclds the highest pregnancy rate.

Key words: ICSI, oocytes, fertilization.

\section{INTRODUCTION}

The use of GnRH agonists for preventing premature $\mathrm{LH}$ surges in controlled ovarian hyperstimulation in IVF/embryo transfer (IVF/ET) has greatly improved the planning of oocyte retrieval (OR). Pituitary function does not resume completely until 2-3weeks after the end of GnRH-agonist characterized by a decline in serum estradiol $\left(E_{2}\right)$ and progesterone 8 days after HCG administration for oocyte maturation ${ }^{(1)}$. This decline in steroids was thought to have a negative eflect on pregnancy rate and exogenous supplementation of progesterone or HCG, i.e. luteal phase support, proved indeed to he mandatory $(2,3)$.

In all available studies the time of onset of administration of parentral progesterone for luteal phase support ranged randomly from the day before OR to 4 days after ET. Only three randomized studies have been performed to assess the impact of the moment of starting luteal phase support on pregnancy rate in GnRH agonist down-regulated IVF

Corresponding author: Ashraf Hany Abdel Rahman, Obstetrics \& Gynecology Dpt, Faculty of Medicine, Alexandria University. 
cycles. In the first study, a decrease of $12 \%$ in regnancy rate was seen when progesterone was started $12 \mathrm{~h}$ before OR compared to $12 \mathrm{~h}$ after OR (4). In the second study, a decrease of $24 \%$ was scen when progesterone support was delayed until 6 days after OR compared to 3 days after $\mathrm{OR}^{(5)}$. In the third study, no difference was found when luteal phase support was started at OR compared to starting at $\mathrm{ET}^{(6)}$.

The chosen time points of the start of progesterone support assessed in these randomized studies, however, did not cover the complete implantation window.

The aim of this study, therefore, was to assess the impact of the onset of progesterone support on ongoing pregnancy rate.

We compared administration of parentral progesterone starting the day before embryo transfer and the day of embryo transfer, in a randomized clinical trial, in infertile patients undergoing treatment with $\mathrm{GnRH}$ agonist down-regulated IVF/ET.

\section{MATERIALS \& METHODS}

The study included 140 women undergoing IVFICSI program for both male and female infertility. These women were counseled about the experimental nature of the protocol, and a signed consent was obtained from every patient and her partner to be included in the study. Patients were randomly divided into two equal groups .

After informed consent, patients were assigned to two different luteal phase support groups and received $200 \mathrm{mg}$ parentral progesterone (prontogest $100 \mathrm{mg}$ IBSA) intamascular (i.m.) starting at the day before embryo transfer or at the day of ET. Parentral Progesterone treatment was continued until the onset of menstruation, or until 18 days following ET. The randomization was performed at a baseline visit by fertility doctors by opening a sealed opaque envelope containing the arm of treatment. The envelopes were prepared and numbered by the main investigator.

The IVF treatment was performed according to a local standard protocol described earlier ${ }^{(7)}$. Venous blood samples for serum $E_{2} \quad(n m o l / l)$ and progesterone $(\mathrm{nmol} / \mathrm{l})$ were drawn at $\mathrm{OR}$ and on the $3^{\text {td }}, 6^{\text {th }}, 9^{\text {th }}, 12^{\text {th }}$ and $18^{\text {th }}$ day after OR and werc assessed with a radioimmunoassay assay (DPC. Los Angeles, CA, USA) for $\mathrm{E}_{2}$ and (Orion Diagnostica. Espoo. Finland) for progesterone.

Biochemical pregnancies were defined as an increase in serum $\mathrm{HCG}>2 \mathrm{IU} / \mathrm{ml}$ or a positıve pregnancy test assessed at the $18^{\text {th }}$ day after oocyte retrieval (Tandem ICON test; Hybritech, San Diego. CA, USA). Clinical pregnancies were defined as a gestational sac seen by transvaginal ultrasound at the 35 th day after oocyte retrieval. Ongoing pregnancies nore abfined as a positive focal heartbeat by transvaginal ultrasound 10 weeks after $O R$.

\section{Statistical Analysis :}

Statistical analysis were performed using the $\chi^{2}$. or t-test as appropriate. All P- values quoted with values $<0.05$ indicate statistical significance. Analysis were performed using the SPSS statistical package (SPSS, Inc, Chicago) .

\section{RESULTS}

The study included 140 women undergoing IVF-ICSI program for male, and/or female infertility. They were randomly divided into two groups : those who received parentral progesterone the day before embryo transfer (Group I), which included 70 women, and those who received parentral progesterone on the day of ET ( Group II), which also included 70 women. Both groups were homogenous as regards age distribution ( 33 years \pm 0.4 in Group I, and 32.7 ycars \pm 0.6 in Group II ) and infertility duration ( $3.5 \pm 1.5$ years in Group $I$ and $3.4 \pm 1.4$ 
years in Group II ). The mean number of the stimulation days, and the retrieved oocytes were not significantly different as shown in table I.

Also the mean number or quality of transferred embryos or the total number of frozen embryos did not show any significant difference as shown in the table.

Mean serum $E_{2}$ and progesterone levels did not differ between the two groups. Lastly, there were no significant differences between the two groups in biochemical, clinical and ongoing pregnancies or live birth rates.

Table I : Impact of day of onset of luteal support on the success of IVF/ET and ICSI.

\begin{tabular}{|l|c|c|c|}
\hline & $\begin{array}{c}\text { Day before } \\
\text { ET (I) }\end{array}$ & $\begin{array}{c}\text { Day of } \\
\text { ET (II) }\end{array}$ & P value \\
\hline Stimulation days (SD) & $9.6(2.7)$ & $9.8(2.4)$ & NS \\
\hline No. of retrieved oocytes (SD) & $10.3(8.4)$ & $9.7(6.6)$ & NS \\
\hline Number of emb. transfered (SD) & $2.1(0.7)$ & $2.2(0.7)$ & NS \\
\hline Number of frozen embryos (SD) & $2.1(3.9)$ & $1.7(3.2)$ & NS \\
\hline$\%$ Biochemical preg. & $30 \%(n=21)$ & $32 \%(n=22)$ & NS \\
\hline$\%$ Clinical preg & $28 \%(n=19)$ & $29 \%(n=20)$ & NS \\
\hline$\%$ On going preg & $22.7 \%(n=15)$ & $23.6 \%(n=16)$ & NS \\
\hline$\%$ Live birth & $21.1 \%(n=14)$ & $20.5 \%(n=14)$ & NS \\
\hline
\end{tabular}

$* \mathrm{P}<0.05$

\section{DISCUSSION}

Synchronization of the fertilized egg and the receptivity of the endometrium, i.c. the implantation window, are regarded as essential in the success rate of IVF/ET (8). In vivo, a small, but distinct, increase of endogenous progesterone is already seen concurrently with the LH surge. After the LH surge, it takes $36-48 \mathrm{~h}$ for progesterone to transform the proliferative endometrium into secretory-phase endometrium. The in vivo fertilized embryo usually arrives at the uterine cavity $72-96 \mathrm{~h}$ after ovulation, leaving sufficient time for the completion of the transformation of the endometrium (9). Compared to in vivo fertilized embryos, the in vitro fertilized embryos arrive earlier in the uterine cavity, i.e. $72 \mathrm{~h}$ after OR. Starting luteal phase support early in order to achieve a more advanced endometrium seems, therefore, preferable $e^{(10)}$. This was also observed in an oocyte donor programme, where the highest pregnancy rates were found in patients who were pretreated with progesterone for at least 3 days $\mapsto r^{\circ}$ more (11).

Another method for achieving synchronization between endometrial receptivity and the embryo is varying the day of ET. A Cochrane review showed significantly higher clinical pregnancy rates of day three transferred embryos versus day two transferred embryos ${ }^{(12)}$. Unfortunatcly, in this review, datit concerning the start of luteal phase support was lacking.

The present randomized study aimed to create two different implantation windows by adjusting the luteal phase of an IVF treatment cycle, while the day of ET was fixed on day 3. As luteal support, we used progesterone administered intramuscularly and not HCG, since HCG significantly increases the risk of ovarian hyperstimulation syndrome (Odds Ratio 
3.06) $(95 \% \text { CI } 1.59-5.86)^{(3)}$ with similar ongoing pregnancy rates.

In conclusion we could not identify, within the chosen time points and within the sample size, a specific implantation window period in which an optimal endometrial receptivity yields the highest pregnancy rate. Further controlled randomized clinical trials are needed to confirm these preliminary data.

\section{Acknowledgments :}

We would like to thank all members staff at the madina infertility centir for there cooporation in this study.

\section{REFERENCES}

1. Smitz J, Devroey P, Braeckmans P, Camus M, Kahn I, Staessen C, Van Waesberghe L, Wisanto $A$ and Van Steirteghem AC. Management of failed cycles in an IVF/GIFT progranme with the combination of a GnRH analoguc and HMG. Hum Reprod 1987; 2, 309-314.

2. Pritts EA and Atwood AK Lutcal phase support in infertility ticatment: a meta-analysis of randomized trials. Hum Reprod 2002; 17, 2287-2299.

3. Daya S and Gunby J Luteal phase support in assisted reproduction cycles. Cochrane Database Syst Reviews, 2004; Issue 3.

4. Sohn SH, Penzias AS, Emmi AM, Dubey AK, Layman LC, Reindollar RH and DeCherney AH. Administration of progesterone before oocyte retrieval negatively affects the implantation rate. Fertil Steril 1999; 71, 11-14.
5. Williams SC, Ochninger S, Gibbons WE, Van Cleave WC and Muasher SJ Delaying the initiation of progesterone supplementation results in decreased pregnancy rates after in vitro fertilization: a randomized, prospective study. Fertil Steril 2001: $76,1140-1143$.

6. Baruffi R, Mauri AL, Petersen CG, Felipe V and Franco JG Jr. Effects of vaginal progesterone administration starting on the day of oocyte retrieval on pregnancy rates. J Assist Reprod Genet 2003; 20, 51720 .

7. Repping S, Van Weert JM, Mol BW, DeVries JW and Van der Veen F. Use of the total motile sperm count to predicl total fertilization failure in in vitro fertilization. Fertil Steril 2002; 78, 22-28 .

8. Bourgain $C$ and Devroey $P$ The endometrium in stimulated cycles for IVF. Hum Reprod Update 2003: 9, 515-522.

9. Croxatto HB, Ortiz ME, Diaz S, Hess R, Balmaceda J and Croxalto HD Studies on the duration of egg transport by the human oviduct. II. Ovum location at various intervals following luteinizing hormone peak. Am J Obstet Gynecol 1978; 15, 629-634.

10. Garcia JE, Acosta AA, Hsiu JG and Jones HW Jr . Advanced endometrial maturation after ovulation induction with human menopausal gonadotropin/ human chotionic gonadotropin for in vitro fertilization. Fertil Steril 1984; 41, 31-35.

11. Prapas Y, Prapas N, Jones EE, Duleba AJ, Olive DL, Chatziparasidou A and Vlassis G. The window for embryo transfer in oocyte donation cycles depends on the duration of progesterone therapy. Hum Reprod 1998; 13, 720-723.

12. Oatway C, Gunby J and Daya S (2004) Day three versus day two embryo transfer following in vitro fertilization or intracytoplasmic sperm injection. Cochrane Database Syst Reviews, Issue 2. 